$$
\text { Pontifícia Universidade C Católica }
$$

Frederico de Arruda Falcão

Estratégias e Táticas de Negociação Utilizadas por Profissionais no Contexto atual

Dissertação de Mestrado

Dissertação apresentada como requisito parcial para obtenção do grau de Mestre pelo Programa de Pósgraduação em Administração de Empresas do Departamento de Administração da PUC-Rio.

Orientador: Prof. José Roberto Gomes da Silva

Rio de Janeiro

Novembro de 2006 


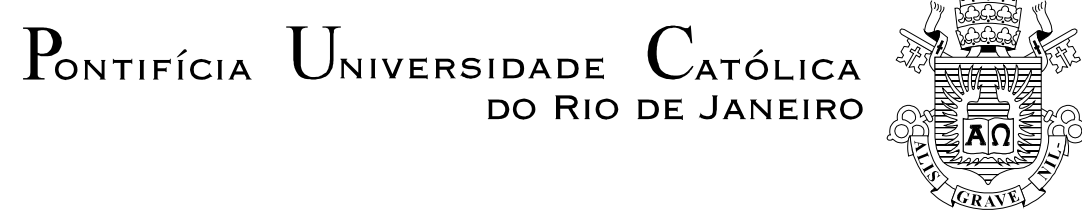

Frederico de Arruda Falcão

\section{Estratégias e Táticas de Negociação Utilizadas por Profissionais no Contexto atual}

Dissertação apresentada como requisito parcial para obtenção do grau de Mestre pelo Programa de Pósgraduação em Administração de Empresas da PUC-Rio. Aprovada pela Comissão Examinadora abaixo assinada.

Prof. Mario Couto Soares Pinto

Departamento de Administração - PUC-Rio

Prof. Mônica Zaidan Gomes Rossi

FACC - UFRJ

Prof. João Pontes Nogueira

Vice-Decano de Pós-Graduação do CCS

Rio de Janeiro, 14 de novembro de 2006 
Todos os direitos reservados. É proibida a reprodução total ou parcial do trabalho sem autorização da universidade, do autor e do orientador.

\section{Frederico de Arruda Falcão}

Graduou-se em Engenharia Elétrica de Produção com ênfase em Telecomunicações na PUC-Rio (Pontifícia Universidade Católica) em 2003. Trabalhou com TI na PUC-Rio, como suporte técnico, e depois na Telemar, com SAP. Em 2002 passou a trabalhar na Engenharia da TIMRio, auxiliando no gerenciamento do projeto de implantação da rede. Foi transferido para a área de Planejamento e Qualidade Comercial, atuando como analista e staff do Presidente. Em 2004 passou a trabalhar na Holding no Brasil da TIM Celular na área de Planejamento e Controle Financeiro, como analista de custos. Atualmente é responsável pela área de Planejamento e Controle Financeiro no Comitê Olímpico Brasileiro, que assumiu em 2005.

Ficha Catalográfica

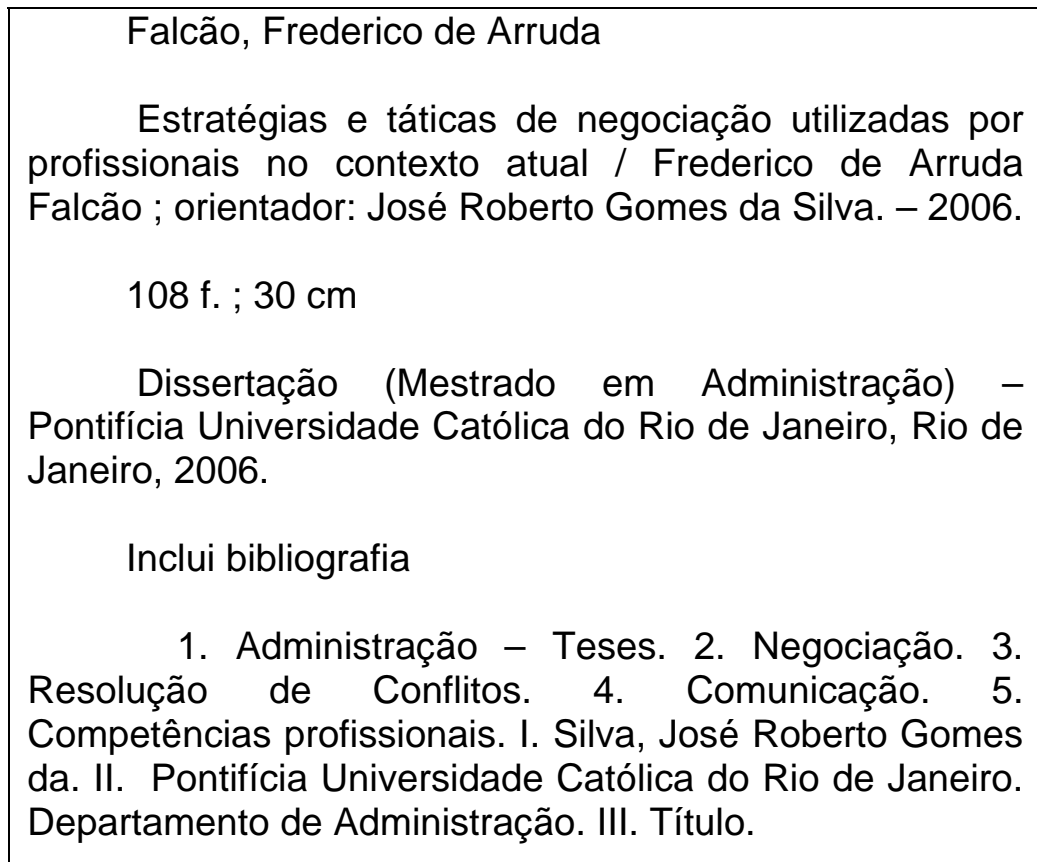

CDD: 658 


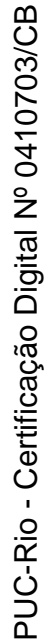

A minha família e amigos que estiveram sempre ao meu lado nos momentos difíceis. 


\section{Agradecimentos}

Ao concluir uma árdua tarefa como essa, não há como deixar de agradecer a todos que contribuíram de alguma forma para o seu desenvolvimento.

A minha avó, pai, mãe e irmãos que me ajudaram de diferentes maneiras seja com apoio, motivação e inspiração, que foram fundamentais nesse momento em minha vida.

Ao meu chefe que acreditou em mim, nesse período em que tive que dividir o tempo do trabalho com o Mestrado, e continuou reconhecendo e investindo no meu trabalho.

Aos meus amigos que estavam sempre presentes e me motivação nos momentos difíceis. Em especial ao J.C.M.

A todos os entrevistados, agradeço a atenção com que me atenderam e todo apoio prestado.

Também agradeço ao meu orientador Prof. José Roberto Gomes, obrigado por toda a orientação, críticas, incentivo e compreensão fornecidos durante toda a jornada e por ter aceitado uma tarefa desafiadora.

Um agradecimento especial para aqueles que viabilizaram esse trabalho: Carlos Serpa, Roberto Migani, Letícia Migani e Tiziani Migani.

Muito Obrigado! 


\section{Resumo}

Falcão, Frederico de Arruda; da Silva, José Roberto Gomes (Orientador). Estratégias e Táticas de Negociação Utilizadas por Profissionais no Contexto atual. Rio de Janeiro, 2006. 108p. Dissertação de Mestrado Departamento de Administração, Pontifícia Universidade Católica do Rio de Janeiro.

Na tentativa de sobreviver e prosperar num mercado supercompetitivo e num ambiente caracterizado por mudanças e incertezas como o atual, as organizações precisam ser capazes de mudar a si próprias. O mercado e o ambiente estão mudando numa velocidade cada vez maior exigindo que as organizações sejam ágeis em suas mudanças. No processo de implementação da mudança há uma série de negociações que vão definindo o rumo do que tinha sido previamente planejado. Dessa forma, se a organização não possui funcionários com competência em negociação a mudança pode demorar a ocorrer e não sair conforme o planejado. Esse trabalho aborda o modo como os profissionais atualmente estão negociando em seu ambiente de trabalho e se propôs a identificar as estratégias e táticas de negociação mais utilizadas pelos profissionais nos diferentes contextos de seu cotidiano. Trata-se de um tema que, embora seja objeto de interesse significativo na literatura internacional de gestão, não tem sido tão significativamente abordado nas pesquisas no Brasil. A pesquisa envolveu entrevistas com 13 profissionais com funções diferentes e de mercados variados. Os resultados mostraram que, entre os profissionais investigados há estratégias e táticas variadas de ação nas negociações, em função dos diferentes contextos. Foi possível, no entanto, identificar um conjunto de aspectos percebidos pelos indivíduos como importantes para o sucesso da negociação, envolvendo desde a preparação até a resolução de situações em que ocorrem impasses ou a necessidade de abandonar o processo.

\section{Palavras-chave}

Negociação; Resolução de Conflitos; Comunicação; Competências profissionais. 


\section{Abstract}

Falcão, Frederico de Arruda; da Silva, José Roberto Gomes (Advisor). Negotiation Strategies and Tactics used by Professionals in today's context. Rio de Janeiro, 2006. 108p. MSc Dissertation - Departamento de Administração, Pontifícia Universidade Católica do Rio de Janeiro.

In order to survive and prosper in a very competitive market and in an environment characterized by changes and uncertainty like nowadays, the organizations need to be able change itself. The market and the environment are changing faster demanding the organizations to be more agile in their changes. In the process to implement the change there are a lot of negotiations that define the course of what had been planed before. So if the organization doesn't have employees with negotiation skills, the change might take longer to happen and it might not come as planed. This work's theme is about the way the professional are negotiating nowadays in their work and has the main goal of identifying negotiation strategies and tactics that the professionals use the most in the different contexts. Although the interest for this theme is very significant in the international management literature it have not been significantly broached in researches in Brazil. The research involved interviews with 13 professionals with different jobs and working in different markets. The results show that depending on the context there is a variety of strategies and tactics among the professionals investigated. It was possible to identify a group of aspects perceived by the individuals as important for the success of the negotiation, going through the preparation phase until situations when there is an impasse or when the person has to leave the process.

\section{Keywords}

Negotiation; Conflict Resolution; Communication; Professional Competences. 


\section{Sumário}

1. Descrição do Problema 11

1.1. Introdução 11

1.2. Objetivo 14

1.3. Relevância da Pesquisa 15

1.4. Delimitação do Estudo 17

$\begin{array}{ll}\text { 1.5. Estrutura da Dissertação } & 18\end{array}$

2. Referencial Teórico 19

2.1. A Noção de Conflito 19

2.2. O Conceito de Negociação 20

2.3. Estratégias e Táticas de Negociação $\quad 22$

2.3.1. Frames e Modelos Mentais em Negociação 22

2.3.2. Liderança na Negociação $\quad 25$

2.3.3. A arte da Discussão na Negociação $\quad 26$

2.3.4. Humor nas Negociações $\quad 28$

2.3.5. Momentos Críticos em uma Negociação 30

2.3.6. Quando Desistir de uma Negociação 31

2.3.7. Negociação com Pessoas Difíceis 35

2.3.8. Ameaças como Tática de negociação 39

2.3.9. Abertura de Negociações 43

2.3.10. Prazos e Pressa numa Negociação 46

2.4. Fatores Importantes para o Sucesso de Uma Negociação 49

2.5. Competência $\quad 54$

3. Metodologia de Pesquisa $\quad 57$

3.1. Pesquisa Qualitativa em Negociação Profissional 57

3.2. Tipo de Pesquisa $\quad 58$

3.3. Seleção dos Sujeitos $\quad 59$

3.4. Coleta de Dados $\quad 60$

3.5. Tratamento e Análise dos Dados 64

3.6. Limitações do Método 65

4. Análise dos Resultados $\quad 67$

4.1. Conceitos Básicos de Negociação

4.2. Noção de Sucesso na Negociação 70

4.3. Estratégias e Táticas de Negociação em Diferentes Contextos 72

4.3.1. A Preparação para a Negociação 73

4.3.2. Estratégias de Negociação com Pessoas Difíceis 74

4.3.3. Estratégias de Negociação com Pessoas Defensivas 76

4.3.4. Estratégias Face à Percepção de Argumentos Falsos 77

4.3.5. Formas de Lidar com a Pressão dos Prazos $\quad 79$

4.3.6. Formas de Lidar com a Ansiedade e as Primeiras Impressões 81

4.3.7. Percepções Sobre o Uso do Poder em uma Negociação 83

4.3.8. Táticas com Relação à Troca de Informações 85

4.3.9. Percepções Sobre o Uso do Humor 87 
4.3.10. Formas de Lidar com Impasses

89

4.4. Fatores que Influenciam o Resultado de uma Negociação

5. Conclusão

Referências Bibliográficas 


\section{Lista de quadros}

Quadro 1 - Perfil dos entrevistados

Quadro 2 - Resumo das Estratégias e Táticas nos Diferentes contextos

Profissionais relatadas pelos Entrevistados. 